\title{
MICRO WIRE ELECTRICAL DISCHARGE MACHINING OF TITANIUM ALLOY Ti-6AI-4V
}

\author{
Adrian KOPYTOWSKI, Dorota ONISZCZUK-ŚWIERCZ, Rafał ŚWIERCZ, Rafał NOWICKI, \\ Tomasz CHMIELEWSKI, Tadeusz SAŁACIŃSKI
}

\author{
Warsaw University of Technology, Faculty of Production Engineering, Poland, EU \\ doo@meil.pw.edu.pl
}

https://doi.org/10.37904/metal.2019.968

\begin{abstract}
Micro mechanisms belong to innovative solutions used in many branches of industry, ranging from aviation and cosmonautics, through the automotive and medical industries. The manufacturing of micro and nanostructures requires the use of precision machining. An important role in manufacturing micro parts has electrical discharge machining (EDM). Micro - EDM is a nonconventional method of removing material, using the phenomenon of electric discharges occurring between two electrodes in the presence of a dielectric. Application in the process working electrode in the form of a thin wire $(0.1 \mathrm{~mm})$ allows cutting complex shape microelements. The paper presents the result of the micro wire electrical discharge machining of titanium alloy Ti-6Al-4V. Response surface methodology (RSM) was used to build empirical models of the influence of pulse time $t_{\text {on }}$, wire tension $W T$, wire speed $W S$ on the roughness $R a$ and the cut speed $V$ during machining titanium alloy Ti-6Al-4V.
\end{abstract}

Keywords: Micro WEDM, cut speed, surface roughness,

\section{INTRODUCTION}

The miniaturisation of systems and parts is one of the recent trends in many industrial applications. One of the major limitations of the developed new micro mechanism is the possibilities of the manufacturing process. Conventional technologies like milling, grinding due to the geometry of the tool and process kinematics, it is difficult to use in the processing of micro parts [1-4]. New solutions are therefore sought, including the use of nonconventional technologies like laser beam machining [5], electrochemical machining [6], electrical discharge machining [7-9], to produce micro parts. An important role in manufacturing micro parts has wire electrical discharge machining (WEDM). Wire electrical discharge machining (WEDM) is wieldy using manufacturing difficult to machining conductive materials. In micro WEDM material is removed by a series of discharges occurring in the gap between thin wire electrode $(0.1 \mathrm{~mm})$ and the workpiece. During the WEDM process, the electrodes are insulated from each other by the flowing dielectric (deionized water). Removal mechanism of the material in electrical discharge machining is mainly the result of the electrical discharge which causes melting and evaporation in local surface layers of both the workpiece and the working electrode [10-12]. The heat also causes evaporation of the dielectric liquid and induces high-pressure waves which wash the molten and/or vaporized metal. During discharge local temperature increase to $6000-7000 \mathrm{~K}$ which causes melting and vaporization of the material. During the machining, there are hundreds of electrical discharges which formed specific surface texture, by overlapping of craters from single discharges. Stochastic nature of electrical discharges causes that many works are focused on indicating most favorable parameters and conditions of micro WEDM depending on cutting geometry accuracy [13], surface roughness [14,15]. However, the mico WEDM of titanium alloy Ti-6Al-4V is not enough described. Therefore, this work analyses the impact of the following parameters of micro WEDM pulse time ton, wire tension WT, wire speed WS on the roughness $\mathrm{Ra}$ and cut speed $\mathrm{V}$ was conducted. Furthermore, the developed regression models of micro WEDM will allow the selection of the most favorable processing conditions. 


\section{MATERIALS AND METHODS}

Industry applications of microwire electrical discharge machining are limited by the obtained surface roughness and cut speed. The main object of the study was the developed mathematical models of influence WEDM parameters such as: pulse time $t_{o n}$, wire speed WS and wire tension WT on the roughness Ra and the cutting speed $V$ during machining of titanium alloy. To achieve this goal, experimental research was carried out using a Box Behnken design of the experiment, three-level three parameters design. The choice of this type of experiment reduces the number of experimental runs required to generate sufficient information for a statistically adequate result. Experimental investigations were carried out on the WEDM machine of Charmilles Robofill 440. The cutting samples of titanium alloy Ti-6Al-4V have dimensions of $10 \times 5 \times 5 \mathrm{~mm}$, the electrode was a brass wire with diameter $0.1 \mathrm{~mm}$ and deionized water was used as the dielectric. Roughness parameters were measured on the Talysurf series 2 scanning profilometer. Cut speed $V$ was calculated by dividing the length of the cutting path by the cutting time. The results of the experimental studies are presented in Table 1.

Table 1 Design of the experimental matrix

\begin{tabular}{|c|c|c|c|c|c|}
\hline \multirow{2}{*}{ No. } & \multicolumn{3}{|c|}{ WEDM paramters } & \multicolumn{2}{c|}{ Observed values } \\
\cline { 2 - 6 } & $\boldsymbol{t}_{\text {on }}(\mu \mathrm{s})$ & $\boldsymbol{W B}(\mathrm{daN})$ & $\boldsymbol{W S}(\mathrm{m} / \mathrm{min})$ & $\boldsymbol{R}(\boldsymbol{\mu m})$ & $\boldsymbol{V}(\mathrm{m} / \mathrm{min})$ \\
\hline 1. & 0.2 & 0.3 & 8 & 1.31 & 1.666 \\
\hline 2. & 0.4 & 0.3 & 8 & 1.83 & 5.646 \\
\hline 3. & 0.2 & 0.5 & 8 & 1.33 & 1.696 \\
\hline 4. & 0.4 & 0.5 & 8 & 1.98 & 5.392 \\
\hline 5. & 0.2 & 0.4 & 4 & 1.41 & 1.717 \\
\hline 6. & 0.4 & 0.4 & 4 & 1.95 & 5.729 \\
\hline 7. & 0.2 & 0.4 & 12 & 1.41 & 1.626 \\
\hline 8. & 0.4 & 0.4 & 12 & 2.02 & 5.222 \\
\hline 9. & 0.3 & 0.3 & 4 & 1.55 & 5.199 \\
\hline 10. & 0.3 & 0.5 & 4 & 1.66 & 5.251 \\
\hline 11. & 0.3 & 0.3 & 12 & 1.69 & 5.174 \\
\hline 12. & 0.3 & 0.5 & 12 & 1.73 & 4.898 \\
\hline 13. & 0.3 & 0.4 & 8 & 1.63 & 4.985 \\
\hline 14. & 0.3 & 0.4 & 8 & 1.67 & 4.942 \\
\hline 15. & 0.3 & 0.4 & 8 & 1.62 & 4.981 \\
\hline
\end{tabular}

\section{RESULTS AND DISCUSSION}

Investigation of the influence of the micro WEDM parameters on the roughness Ra and the cut speed $V$ was carried out using response surface methodology (RSM). Regression models were built to predict the influence of investigated parameters on independent variables. Analysis of fitting different types of response function to experimental result indicates that the best fit was found for the polynomial function of the second degree:

$Y=\beta_{0}+\sum_{i=1}^{k} \beta_{i} X_{i}+\sum_{i=1}^{k} \beta_{i} i X_{i}^{2}+\sum_{i=1, i \neq j}^{k} \beta_{i j} i X_{i} X_{j}+\varepsilon$

The analysis of variance (ANOVA) was used to check the significance of the independent variable in the model. The ANOVA test was conducted at a $95 \%$ coefficient level. If probability (Prob $>f$ ) value for each factor was less than 0.05 , this indicated that the model factor was significant (i.e., at a $95 \%$ confidence level). Values of 
Prob $>f$ higher than 0.05 indicated that a model factor was non-significant and should be removed from response function. After removing not significant factor the ANOVA test was conducted again for a new function (without non-significant terms). The ANOVA results for the regression equation of roughness $R a$ and cut speed $V$, present in Tables 2 and 3, respectively. For each response function, the coefficient of determination, $R^{2}$ and the adjusted coefficient of determination, $R^{2}$-Adj was calculated. These coefficients represented the percentage of variance explained by the model. For $R^{2}$ and $R^{2}$-Adj approaches unity, the response function is more accurate fit to the research results. The results implied that all the developed models were significant at a $95 \%$ confidence level.

Table 2 ANOVA table for the Ra

\begin{tabular}{|c|c|c|c|c|c|}
\hline Source & $\begin{array}{c}\text { Sum of } \\
\text { squares }\end{array}$ & $\begin{array}{c}\text { Degrees of } \\
\text { freedom }\end{array}$ & Mean square & F-Value & Prob $>\boldsymbol{f}$ \\
\hline $\boldsymbol{t}_{\mathrm{n}}$ & 0.6728 & 1 & 0.6728 & 444.931 & 0.0000 \\
\hline $\boldsymbol{W S}$ & 0.0098 & 1 & 0.0098 & 6.480 & 0.0290 \\
\hline $\boldsymbol{W S}^{2}$ & 0.0105 & 1 & 0.0105 & 6.991 & 0.0245 \\
\hline $\boldsymbol{W T}$ & 0.0128 & 1 & 0.0128 & 8.464 & 0.0155 \\
\hline Error & 0.0151 & 10 & 0.0015 & & $R^{2}$-Adj $=0.97$ \\
\hline Total SS & 0.7210 & 14 & \multicolumn{2}{|c|}{$R^{2}=0.98$} \\
\hline
\end{tabular}

Table 3 ANOVA table for the $V$

\begin{tabular}{|c|c|c|c|c|c|}
\hline Source & $\begin{array}{c}\text { Sum of } \\
\text { squares }\end{array}$ & $\begin{array}{c}\text { Degrees of } \\
\text { freedom }\end{array}$ & Mean square & F-Value & Prob $>\boldsymbol{f}$ \\
\hline $\boldsymbol{t}_{\text {on }}$ & 29.20008 & 1 & 29.20008 & 18822.57 & 0.000000 \\
\hline $\boldsymbol{t}_{\text {on }}{ }^{2}$ & 7.90470 & 1 & 7.90470 & 5095.42 & 0.000000 \\
\hline $\boldsymbol{W} \boldsymbol{S}$ & 0.11907 & 1 & 0.11907 & 76.75 & 0.000321 \\
\hline $\boldsymbol{W S}^{2}$ & 0.01674 & 1 & 0.01674 & 10.79 & 0.021835 \\
\hline $\boldsymbol{W} \boldsymbol{T}$ & 0.02509 & 1 & 0.02509 & 16.17 & 0.010106 \\
\hline $\boldsymbol{W} \boldsymbol{T}^{2}$ & 0.03251 & 1 & 0.03251 & 20.96 & 0.005960 \\
\hline $\boldsymbol{t}_{\text {on }} \boldsymbol{W} \boldsymbol{S}$ & 0.04326 & 1 & 0.04326 & 27.89 & 0.003242 \\
\hline $\boldsymbol{t}_{\text {on }} \boldsymbol{W} \boldsymbol{T}$ & 0.02016 & 1 & 0.02016 & 13.00 & 0.015457 \\
\hline $\boldsymbol{W S} \boldsymbol{W} \boldsymbol{T}$ & 0.02690 & 1 & 0.02690 & 17.34 & 0.008792 \\
\hline Error & 0.00776 & 5 & 0.00155 & & \\
\hline Total SS & 37.60705 & 14 & \multicolumn{2}{|c|}{$R^{2}=0.99$} \\
\hline
\end{tabular}

After eliminating non significant terms in the regression equation for the roughness $R a$ and $V$, the following response function was obtained:

$\mathrm{Ra}=0.737+2.9$ ton $+0.044 \mathrm{WS}+0.0033 \mathrm{WS} 2+0.205 \mathrm{WS}$ WT

$V=-13.824+111.81$ ton -146.31 ton2 + 0.062 WS + 0.0042 WS2 - 4.29 WT + 9.38 WT2 -

-0.26 ton WS -7.1 ton WT -0.205 WS WT

Obtained ANOVA results indicate that the values of the $R^{2}$ for the roughness $R a$ and the cut speed $V$ were over $98 \%$ and $99 \%$, respectively. The result shows that the regression models provided an excellent explanation of the relationship between the pulse time $t_{\text {on }}$, wire speed $W S$, wire tension $W T$ and the response $R a$ and $V$. The difference between coefficient of determination and the adjusted coefficient of determination, 
is smaller than 0.1 , which indicated that the established models were adequate and representing the process. Performed residual analyses indicate that the fit of the response model of the roughness $R a$ and the cut speed $V$ to experimental results is very good. The normal probability plots of residuals (Figures 1a, 2a) shows that the correlation between predicted and experimental data is good (experimental data is distributed approximately along a straight line). The plots of residuals versus the predicted values (Figures $\mathbf{1 b} \mathbf{b} \mathbf{2 b}$ ) and the residuals versus the case number values (Figures 1c, 2c) indicate that the residuals did not follow any trend and they have a stochastic nature. The plotted residuals versus the case number show that the error terms were independent of one another. The analysis of the residuals plots indicates that the developed models were adequate from a statistical point of view.

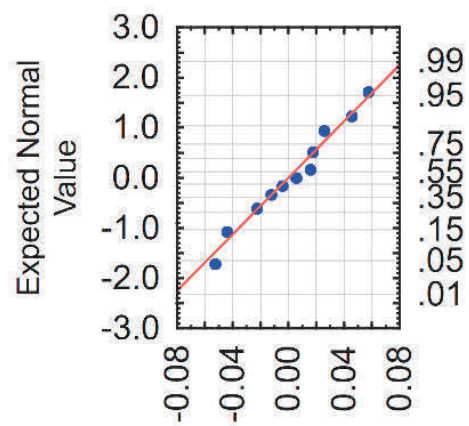

Residual

(a)

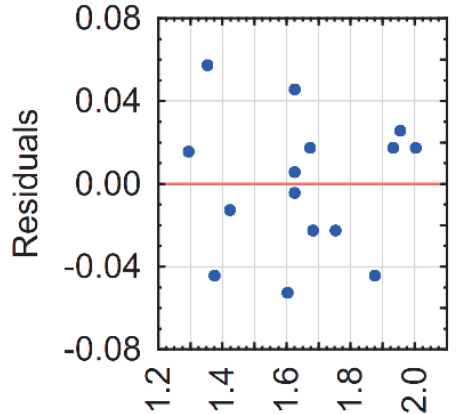

Predicted Values

(b)

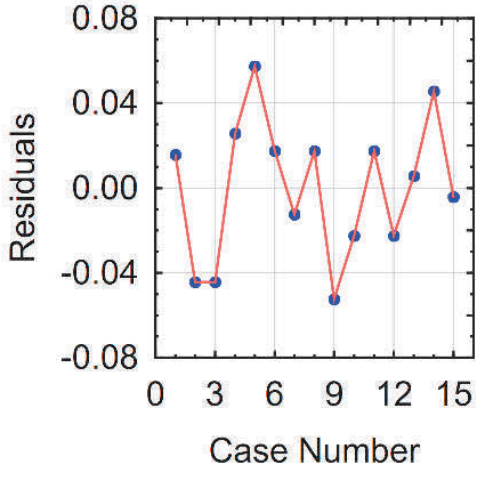

(c)

Figure 1 Plots of residuals for roughness Ra model: (a) the normal plot of residuals, (b) the residuals versus the predicted values and (c) the residuals versus case number

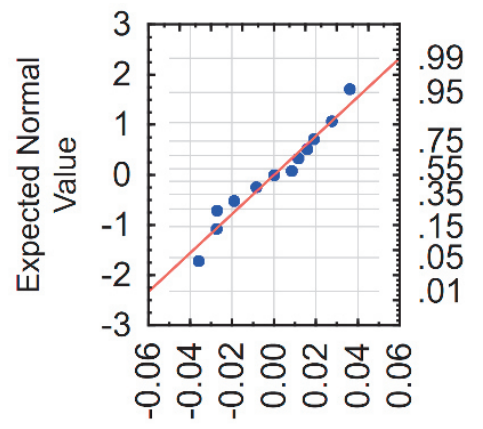

Residual

(a)

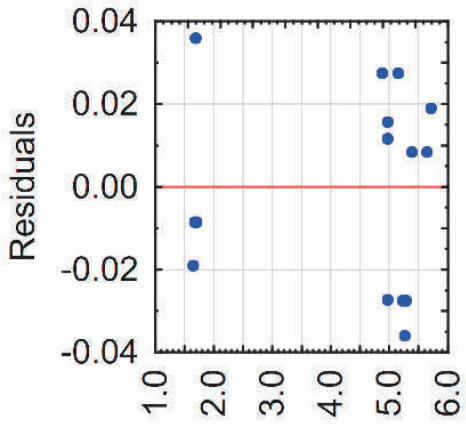

Predicted Values

(b)

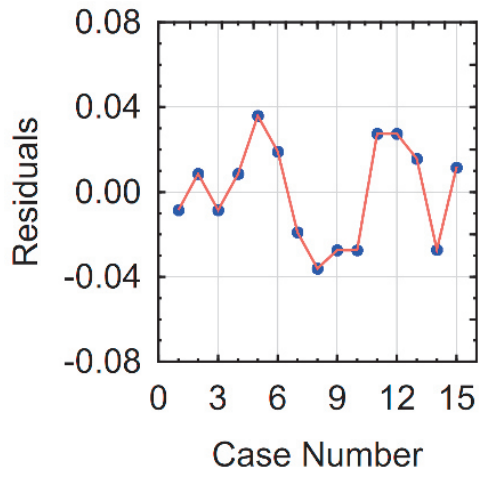

(c)

Figure 2 Plots of residuals for cut speed $V$ model: (a) the normal plot of residuals, (b) the residuals versus the predicted values and (c) the residuals versus case number

To better understanding the influence of the micro WEDM parameters on the roughness $R a$ and the cut speed $V$, the response surface plots were estimated. Based on the regression models (equations 2 - 3 ), the influence of the pulse time $t_{o n}$, wire speed $W S$ and wire tension $W T$ on the $R a$ and the $V$ is shown in Figures 3,4 respectively. The conducted experimental studies indicated that the main parameters that influenced roughness $R a$ and cut speed $V$ was the pulse time (Figures 3,4 ). The roughness $R a$ and the speed cut $V$ increase with the growth of the pulse time. With the increase of the pulse time, the amount of energy delivered to the workpiece causes the melting and evaporation of a higher volume of material, which generates a crater with a larger depth. This leads to obtain a higher value of roughness height parameter Ra. The presented dependence also has effects on the speed cut. The increased pulse time corresponded to an increase in the 
amount of eroded material in a single impulse. The result of experimental studies shows that wire speed WS and wire tension $W T$ do not have a significant influence on the roughness high and speed cut.

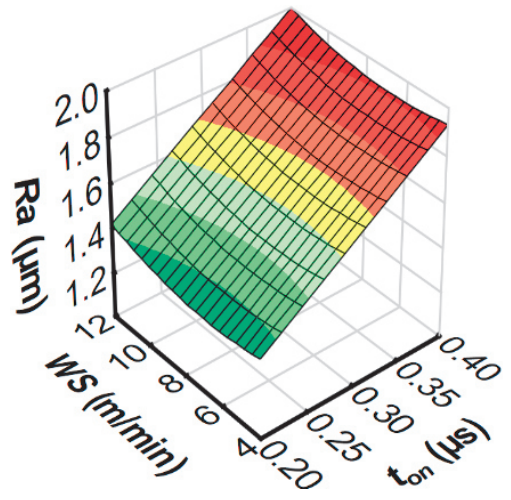

(a)

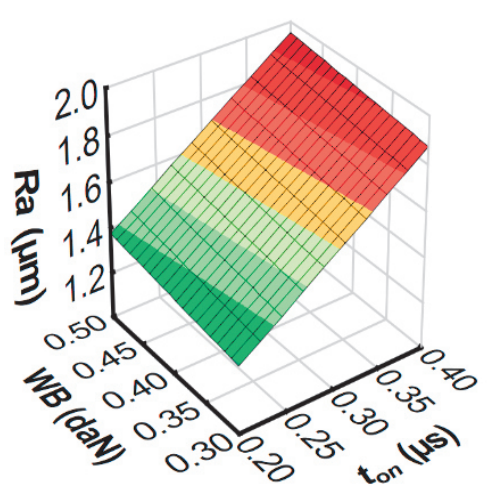

(b)

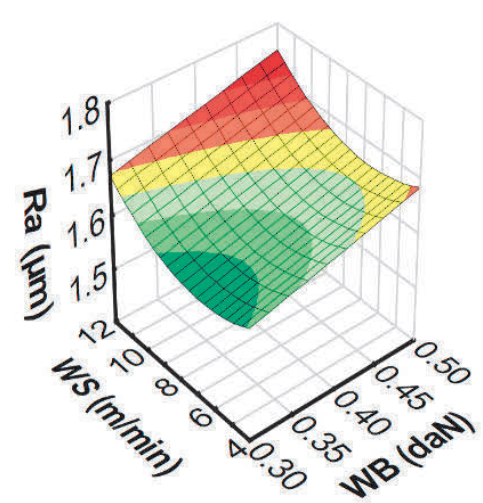

(c)

Figure 3 Estimated response surface plot for the roughness Ra: (a) constant $W B=0.4$ daN,

(b) constant $W S=8 \mathrm{~mm} / \mathrm{min}$ and (c) constant $t_{\mathrm{on}}=0.3 \mu \mathrm{s}$

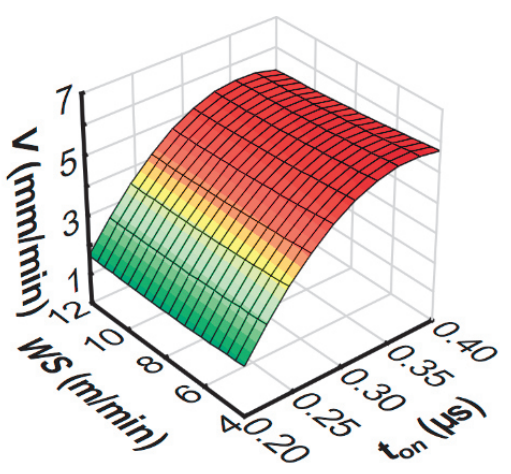

(a)

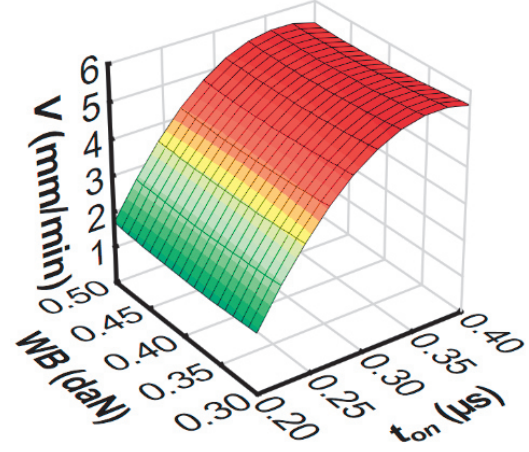

(b)

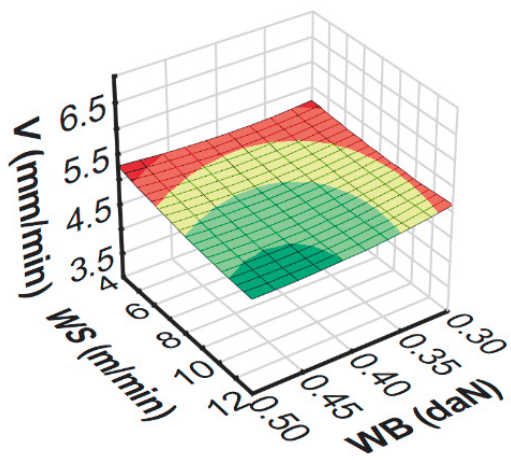

(c)

Figure 4 Estimated response surface plot for the cut speed $V$ : (a) constant $W B=0.4$ daN;

(b) constant $W S=8 \mathrm{~mm} / \mathrm{min}$ and (c) constant $t_{\mathrm{on}}=0.3 \mu \mathrm{s}$

\section{CONCLUSIONS}

Conducted experimental studies were focused on the analyses of influence micro WEDM parameters on the roughness $R a$ and speed cut $V$ during machining of titanium alloy Ti-6Al-4V. Based on the theoretical analyses and experimental research, the following conclusions were obtained:

- The roughness parameter Ra was the range of $1.31-2.02 \mu \mathrm{m}$ and corresponded to finishing and semi finishing machining. Ra was mainly dependent on the pulse time. Furthermore, the increase of pulse time increased the amount of eroded material in a single pulse, thus leading to higher roughness. The presented dependence also has effects on the speed cut.

- The developed regression equations could be used in micro wire electrical discharge machining of titanium alloy Ti-6AI-4V as a guideline for the selection of WEDM parameters.

\section{ACKNOWLEDGEMENTS}

This study was conducted with financial support from the Fundamental Research Funds of Institute of Manufacturing Technology Warsaw University of Technology, hereby gratefully acknowledged. 


\section{REFERENCES}

[1] VILČEK, I., ŘEHOŘ, J., CAROU, D. and ZEMAN, P. Residual stresses evaluation in precision milling of hardened steel based on the deflection-electrochemical etching technique. Robotics and Computer-Integrated Manufacturing. 2017. 47, pp. 112-116. [viewed 2019-02-15]. Available from: DOI:10.1016/j.rcim.2016.10.001

[2] HLAVÁČ, L. M., KRAJCARZ, D., HLAVÁČOVÁ, I. M. and SPADŁO, S. Precision comparison of analytical and statistical-regression models for AWJ cutting. Precision Engineering. 2017. vol. 50, pp. 148-159 [viewed 2018-0306]. Available from: DOI:10.1016/j.precisioneng.2017.05.002.

[3] BAŃKOWSKI, D. and SPADŁO, S. The Aplication of Vibro - Abrasive Machining for Smoothing of Castings. Archives of Foundry Engineering. 2017. vol. 17, pp. 169-173, [viewed 2018-02-15]. Available from: DOI:10.1515/afe-2017-0031.

[4] CHAUBEY, S.K. and JAIN, N.K. State-of-art review of past research on manufacturing of meso and micro cylindrical gears. Precision Engineering. 2018. vol. 51, pp. 702-728. [viewed 2019-03-15]. Available from: 10.1016/j.precisioneng.2017.07.014

[5] RADZIEJEWSKA, J. Application of a nanosecond laser pulse to evaluate dynamic hardness under ultra-high strain rate. Optics \& Laser Technology. 2016. vol. 78, pp. 125-133 [viewed 2017-11-16]. Available from: DOI: 10.1016/j.optlastec.2015.10.011

[6] GRABOWSKI, M., SKOCZYPIEC, S. and WYSZYNSKI, D. A Study on Microturning with Electrochemical Assistance of the Cutting Process. Micromachines. 2018. vol. 9, p. 357. [viewed 2019-03-16]. Available from: DOI: 10.3390/mi9070357

[7] YU, Z., Li, D., YANG, J., ZENG, Z., YANG, X. and LI, J. Fabrication of micro punching mold for micro complex shape part by micro EDM. Int J Adv Manuf Technol. 2019. vol. 100, pp. 743-749. [viewed 2019-03-16].Available from: DOI:10.1007/s00170-018-2731-1

[8] FENG, W., CHU, X., HONG, Y. and ZHANG, L. Studies on the surface of high-performance alloys machined by micro-EDM. Materials and Manufacturing Processes. 2018. vol. 33, pp. 616-625. [viewed 2019-03-16]. Available from: DOI:10.1007/s00170-018-1711-9

[9] SINGH, A.K., PATOWARI, P.K. and DESHPANDE, N.V. Analysis of micro-rods machined using reverse microEDM. J Braz. Soc. Mech. Sci. Eng. 2018. vol. 41, p. 15. [viewed 2019-03-16]. Available from: 10.1007/s40430018-1519-4

[10] ONISZCZUK-ŚWIERCZ, D. and ŚWIERCZ, R. Surface texture after wire electrical discharge machining. In METAL 2017: Proceedings of 26th International Conference on Metallurgy and Materials. Ostrava: TANGER, 2017, pp. 1400-1406.

[11] ŚWIERCZ, R. and ONISZCZUK-ŚWIERCZ, D. Investigation of the Influence of Reduced Graphene Oxide Flakes in the Dielectric on Surface Characteristics and Material Removal Rate in EDM. Materials. 2019. vol. 12, p. 943. [viewed 2019-04-16]. Available from: DOI:10.3390/ma12060943

[12] ŚWIERCZ, R. and ONISZCZUK-ŚWIERCZ, D. The Effects of Reduced Graphene Oxide Flakes in the Dielectric on Electrical Discharge Machining. Nanomaterials. 2019. vol. 9, p. 335. [viewed 2019-04-16]. Available from: DOI: 10.3390/nano9030335

[13] BADIDA, M., GOMBAR, M., MASLEJOVA, A., SOBOTOVA, L., KMEC, J. and VAGASKA, A. Evaluation of zinc coating quality by statistical methods. Przemysl Chemiczny. 2015. vol. 94, pp. 2146-2149. [viewed 2018-04-16].

[14] WANG, Y., CHEN, X., WANG, Z. and DONG, S. Fabrication of micro gear with intact tooth profile by micro wire electrical discharge machining. Journal of Materials Processing Technology. 2018, vol. 252, pp. 137-147. [viewed 2019-04-16]. Available from: DOI: 10.1016/j.jmatprotec.2017.09.002

[15] CHEN, X., WANG, Z., WANG, Y., CHI, G. and GUO, C. Micro reciprocated wire-EDM of micro-rotating structure combined multi-cutting strategy. Int. J. Adv. Manuf. Technol. 2018. vol. 97, pp. 2703-2714. [viewed 2019-04-16]. Available from:DOI:10.1007/s00170-018-2145-0 